\title{
Natural Approaches for Neurological Disorders-The Neuroprotective Potential of Codium tomentosum
}

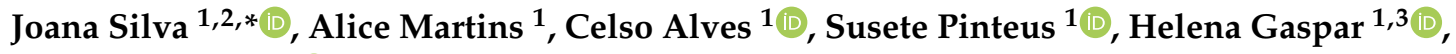 \\ Amparo Alfonso ${ }^{2}$ D and Rui Pedrosa $4, *$ \\ 1 MARE-Marine and Environmental Sciences Centre, Polytechnic of Leiria, 2520-630 Peniche, Portugal; \\ alice.martins@ipleiria.pt (A.M.); celso.alves@ipleiria.pt (C.A.); susete.pinteus@ipleiria.pt (S.P.); \\ hmgaspar@fc.ul.pt (H.G.) \\ 2 Department of Pharmacology, Faculty of Veterinary, University of Santiago de Compostela, \\ 27002 Lugo, Spain; amparo.alfonso@usc.es \\ 3 BioISI-Biosystems and Integrative Sciences Institute, Faculty of Sciences, University of Lisbon, \\ 1749-016 Lisboa, Portugal \\ 4 MARE-Marine and Environmental Sciences Centre, ESTM, Polytechnic of Leiria, \\ 2520-630 Peniche, Portugal \\ * Correspondence: joana.m.silva@ipleiria.pt (J.S.); rui.pedrosa@ipleiria.pt (R.P.); \\ Tel.: +351-262-783-607 (J.S. \& R.P.); Fax: +351-262-783-088 (J.S. \& R.P.)
}

Academic Editors: Elisa Ovidi and Antonio Tiezzi

Received: 3 November 2020; Accepted: 19 November 2020; Published: 23 November 2020

\begin{abstract}
Parkinson's disease (PD) is the second most common neurodegenerative disorder, and is characterized by a progressive degeneration of the dopaminergic neurons in the substantia nigra. Although not completely understood, several abnormal cellular events are known to be related with PD progression, such as oxidative stress, mitochondrial dysfunction and apoptosis. Accordingly, the aim of this study was to evaluate the neuroprotective effects of Codium tomentosum enriched fractions in a neurotoxicity model mediated by 6-hydroxydopamine (6-OHDA) on SH-SY5Y human cells, and the disclosure of their mechanisms of action. Additionally, a preliminary chemical screening of the most promising bioactive fractions of $C$. tomentosum was carried out by GC-MS analysis. Among the tested fractions, four samples exhibited the capacity to revert the neurotoxicity induced by 6-OHDA to values higher or similar to the vitamin E (90.11 $\pm 3.74 \%$ of viable cells). The neuroprotective effects were mediated by the mitigation of reactive oxygen species (ROS) generation, mitochondrial dysfunctions and DNA damage, together with the reduction of Caspase-3 activity. Compounds belonging to different chemical classes, such as terpenes, alcohols, carboxylic acids, aldehydes, esters, ketones, saturated and unsaturated hydrocarbons were tentatively identified by GC-MS. The results show that $C$. tomentosum is a relevant source of neuroprotective agents, with particular interest for preventive therapeutics.
\end{abstract}

Keywords: seaweed; marine natural products; neurodegenerative disease; SH-SY5Y cells; oxidative stress; mitochondrial dysfunction

\section{Introduction}

Neurodegenerative diseases are estimated to surpass cancer as the second most common cause of death among the elderly [1]. For this reason, in recent years there has been a great deal of interest in the search for new, safer, and effective neuroprotective agents that can be used in the therapy of neurodegenerative diseases such as Parkinson's disease (PD) [1,2]. PD is one of the most impactful human diseases without an effective cure, making imperative the research on innovative therapeutics [3]. 
Worldwide, there is a growing interest in the development of more selective and effective therapeutic agents to prevent or to delay the progression of neurodegeneration [4].

PD involves the loss or degeneration of dopaminergic neurons in the substantia nigra pars compacta (SNpc) and the accumulation of Lewy bodies, and abnormal intracellular aggregates containing proteins such as alpha-synuclein, sinfilin-1 and ubiquitin [5]. The etiology of PD remains largely unknown [6]; however, it is assumed that the main mechanisms involved in the development and progression of this disease are associated with oxidative stress, mitochondrial dysfunction, neuroinflammation, and apoptosis, among others, which act together leading to degeneration of dopaminergic neurons [7].

Natural products obtained from marine organisms have been shown to be a potential source of novel therapeutic agents. Among these organisms, macroalgae have been reported for their ability to produce relevant bioactive compounds [8], mainly derived from their secondary metabolism as a defense response to environmental variations [2]. These metabolites are known to exhibit a broad range of bioactive properties such as antioxidant [9], antimicrobial [10], anti-inflammatory [11], anti-tumoral [12], and neuroprotective [13]. Thus, these metabolites can inspire the development of new drugs for the therapy of various pathologies, such as cancer, diabetes, and neurodegenerative diseases [2]. Concerning neurodegenerative disorders, the benefits of seaweed-derived components on the prevention and/or treatment of neurodegeneration were previously reported [14]. Recently, Souza and co-workers [15] reported the neuroprotective activity of kappa-carrageenan isolated from the seaweed Hypnea musciformis on 6-hydroxydopamine (6-OHDA)-induced neurotoxicity on SH-SY5Y cells by modulation of the mitochondrial membrane potential and the decrease of Caspase- 3 activity. Wen and co-workers [16] showed that the compound austrasulfone isolated from the marine soft coral Cladiella australis has potent neuroprotective effects against the 6-OHDA-induced neurotoxicity on the neuroblastoma SH-SY5Y cell line, as well as anti-inflammatory activity on RAW 264.7 macrophage cells. Additionally, studies carried out by Gao and co-workers [17] demonstrated the neuroprotective effect of the sulfated polysaccharide fucoidan on PC12 cells by blocking the $\mathrm{H}_{2} \mathrm{O}_{2}$-induced apoptosis, scavenging ROS formation and reducing lactate dehydrogenase activity. The authors verified that this fucoidan protected the neurocytes against $\mathrm{H}_{2} \mathrm{O}_{2}$-induced apoptosis via reducing $\mathrm{ROS}$ levels and activating PI3K/Akt signaling pathway.

In the present work, the green macroalgae $C$. tomentosum, found in the intertidal zone of the Portuguese coast [18] was evaluated for its ability to produce neuroprotective substances. The number of studies focusing on the biological potential of this species is limited, since only one report has revealed the antioxidant, anti-genotoxic, anti-tumorigenic and hypoglycemic potential of crude ethanolic extracts [18]. On the other hand, Silva and co-workers [13] demonstrated the neuroprotective capacity of $C$. tomentosum methanol and dichloromethane crude extracts, highlighting the need to pursue the investigation focused on the therapeutic potential of this species. Thus, the present work is aimed at the fractionation and identification of the bioactive molecules produced by C. tomentosum, the evaluation of their antioxidant activity, and the understanding of the mechanisms behind their neuroprotective effects.

\section{Results}

\subsection{Yields, Total Phenolic Content and Antioxidant Activity of Codium tomentosum Fractions}

Freeze-dried samples of green seaweed $C$. tomentosum were sequentially extracted overnight with methanol $(\mathrm{MeOH})$ and dichloromethane (DCM) (in a biomass/solvent ratio of 1:40) with constant stirring at room temperature. The resulting solutions were filtrated, and the organic phases were evaporated in a rotary evaporator (IKA HB10), at $30^{\circ} \mathrm{C}$. Each crude extract was fractionated by vacuum liquid chromatography (VLC) affording a total of 14 fractions (MF1-7 and DF1-7, respectively). An overview of extraction and fractionation sequences is depicted in Figure 1.

The amounts of phenolic compounds and the antioxidant activity of all these fractions were evaluated. 


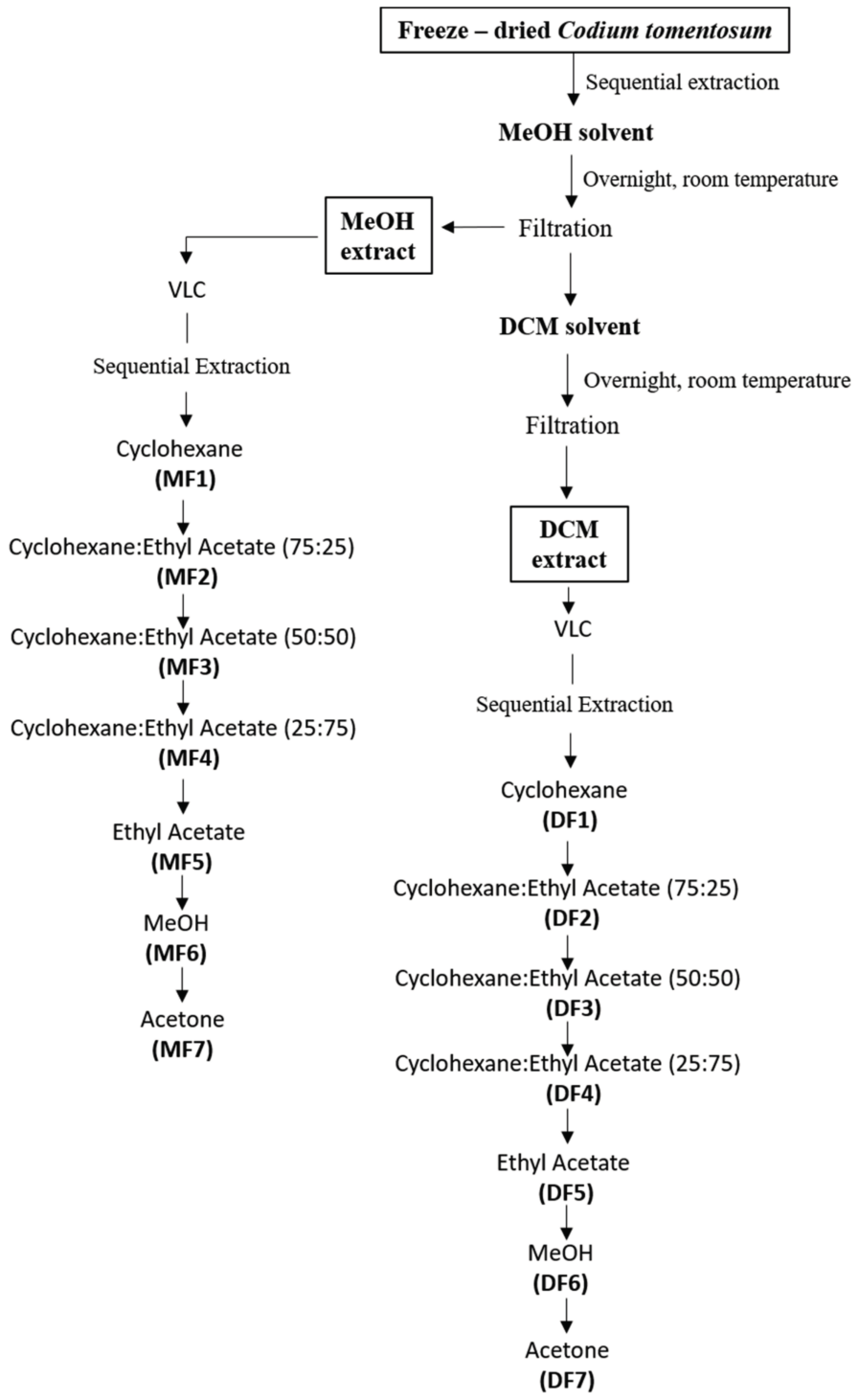

Figure 1. Extraction and fractionation flowchart of the green seaweed Codium tomentosum.

The fractionation yields, the total phenolic content (TPC), and antioxidant capacity assessed through 2,2-diphenyl-1-picrylhydrazyl radical (DPPH) scavenging activity, oxygen radical absorbance capacity (ORAC), and ferric reducing antioxidant power (FRAP) assays of the different fractions obtained from the green seaweed C. tomentosum are summarized in Table 1.

Table 1. Fractionation yields, TPC, and antioxidant capacity of Codium tomentosum fractions.

\begin{tabular}{ccccccc}
\hline Crude Extract & Fraction & Yield (\%) & TPC $^{\mathbf{a}}$ & DPPH $^{\mathbf{b}}$ & FRAP $^{\mathbf{c}}$ & ORAC $^{\mathbf{d}}$ \\
\hline & MF1 & 0.09 & $2.24 \pm 0.15$ & $>100$ & $282.87 \pm 14.27$ & $99.91 \pm 0.57$ \\
\cline { 2 - 7 } & MF2 & 3.29 & $3.96 \pm 0.26$ & $>100$ & $288.40 \pm 11.42$ & $28.92 \pm 0.51$ \\
\cline { 2 - 7 } MeOH & MF3 & 0.88 & $2.58 \pm 0.13$ & $>100$ & $282.99 \pm 2.51$ & $52.60 \pm 1.28$ \\
\cline { 2 - 7 } & MF4 & 0.57 & $7.30 \pm 0.47$ & $>100$ & $271.33 \pm 7.34$ & $74.76 \pm 0.48$ \\
\cline { 2 - 7 } & MF5 & 0.65 & $4.32 \pm 0.30$ & $>100$ & $273.01 \pm 1.81$ & $66.32 \pm 0.95$ \\
\cline { 2 - 7 } & MF6 & 6.73 & $4.38 \pm 0.12$ & $>100$ & $292.73 \pm 3.73$ & $72.73 \pm 1.36$ \\
\hline
\end{tabular}


Table 1. Cont.

\begin{tabular}{ccccccc}
\hline Crude Extract & Fraction & Yield (\%) & TPC $^{\mathbf{a}}$ & DPPH $^{\mathbf{b}}$ & FRAP $^{\mathbf{c}}$ & ORAC $^{\mathbf{d}}$ \\
\hline & DF1 & 0.58 & $4.18 \pm 0.13$ & $>100$ & $24.40 \pm 1.22$ & $38.88 \pm 0.73$ \\
\cline { 2 - 7 } & DF2 & 1.52 & $10.43 \pm 0.40$ & $>100$ & $67.67 \pm 8.05$ & $62.06 \pm 1.67$ \\
\cline { 2 - 7 } $\mathbf{C H}_{\mathbf{2}} \mathbf{C l}_{\mathbf{2}}$ & DF3 & 1.53 & $5.51 \pm 0.75$ & $>100$ & $825.73 \pm 32.59$ & $98.84 \pm 6.00$ \\
\cline { 2 - 7 } & DF4 & 1.00 & $3.51 \pm 0.20$ & $>100$ & $1008.27 \pm 18.18$ & $144.15 \pm 2.02$ \\
\cline { 2 - 7 } & DF5 & 6.35 & $4.30 \pm 0.23$ & $>100$ & $636.21 \pm 22.21$ & $94.56 \pm 1.02$ \\
\cline { 2 - 7 } & DF6 & 13.88 & $4.57 \pm 0.17$ & $>100$ & $356.95 \pm 3.73$ & $165.34 \pm 6.42$ \\
\hline & DHT & 8.58 & $5.69 \pm 0.16$ & $>100$ & $582.11 \pm 20.81$ & $193.85 \pm 14.30$ \\
\hline
\end{tabular}

${ }^{\mathrm{a}}$ mg gallic acid equivalents (GAE)/g extract; ${ }^{\mathrm{b}}$ radical scavenging activity $\left(\mathrm{EC}_{50} \mu \mathrm{g} / \mathrm{mL}\right) ;{ }^{\mathrm{c}} \mu \mathrm{M} \mathrm{FeSO}{ }_{4} / \mathrm{g}$ extract; ${ }^{\mathrm{d}} \mu \mathrm{mol}$ trolox equivalents (TE)/g extract. $\mathrm{EC}_{50}$ values were determined for a $95 \%$ confidence interval. $\mathrm{MeOH}-$ methanol; $\mathrm{CH}_{2} \mathrm{Cl}_{2}$-dichloromethane.

As shown in Table 1, the highest fractionation yields were achieved through the elution with methanol (DF6-13.88\%; MF6-6.73\%), and acetone (MF7-16.90\%; DF7-8.58\%), while lower yields were obtained with the less polar solvent cyclohexane (MF1-0.09\%; DF1-0.57\%).

Regarding the amounts of phenolic compounds, DF2 fraction from dichloromethane crude extract presented the highest TPC $(10.43 \pm 0.40 \mathrm{mg}$ GAE/g extract) followed by MF4 fraction from methanolic crude extract (7.30 $\pm 0.47 \mathrm{GAE} / \mathrm{g}$ extract). On the other hand, MF1 and MF7 fractions presented the lowest TPC ( $2.24 \pm 0.15 \mathrm{GAE} / \mathrm{g}$ extract and $2.47 \pm 0.05 \mathrm{GAE} / \mathrm{g}$ extract, respectively). Concerning the antioxidant activities, none of the fractions demonstrated potential to reduce the DPPH radical. In the ORAC assay, DF7 fraction showed the highest antioxidant activity $(193.85 \pm 14.30 \mu \mathrm{mol} \mathrm{TE} / \mathrm{g}$ extract) followed by DF6 (165.34 $\pm 6.42 \mu \mathrm{mol} \mathrm{TE} / \mathrm{g}$ extract) and DF4 (144.15 $\pm 2.02 \mu \mathrm{mol} \mathrm{TE} / \mathrm{g}$ extract) fractions, respectively. MF2 fraction exhibited the lowest capacity to reduce peroxyl radicals $(28.92 \pm 0.51 \mu \mathrm{mol}$ TE/g extract). Fractions DF3 (825.73 $\pm 32.59 \mu \mathrm{M} \mathrm{FeSO}_{4} / \mathrm{g}$ extract), DF4 (1008.27 $\pm 18.18 \mu \mathrm{M} \mathrm{FeSO}_{4} / \mathrm{g}$ extract) and DF5 (636.21 $\pm 22.21 \mu \mathrm{M} \mathrm{FeSO}_{4} / \mathrm{g}$ extract) revealed the highest efficiency to reduce ferric ions, while the lowest activity was displayed by DF1 $\left(24.40 \pm 1.22 \mu \mathrm{M} \mathrm{FeSO}_{4} / \mathrm{g}\right.$ extract).

\subsection{Neurotoxicity and Neuroprotective Effects of Codium tomentosum Fractions on SH-SY5Y Cells}

The neurotoxic effects of $C$. tomentosum fractions $(100 \mu \mathrm{g} / \mathrm{mL} ; 24 \mathrm{~h})$ were evaluated on SH-SY5Y cells. All the non-toxic fractions were then evaluated for their neuroprotective potential on SH-SY5Y exposed to the neurotoxic effects of 6-OHDA $(100 \mu \mathrm{M})$. Cell viability was estimated by the MTT assay and results are presented in Figure 2.

Among all fractions, only three induced a significant reduction of SH-SY5Y cells' viability (Figure 2A): MF3 from methanolic crude extract (72.27 $\pm 3.56 \%$ of viable cells); DF6 (38.09 $\pm 2.41 \%$ of viable cells) and DF7 (60.02 $\pm 9.66 \%$ of viable cells) from DCM crude extract. Thus, the neuroprotective evaluation was conducted on the remaining non-toxic fractions. The exposition of SH-SY5Y cells to 6-OHDA $(100 \mu \mathrm{M})$ for $24 \mathrm{~h}$ led to a reduction of cell viability of about $42 \%(58.92 \pm 2.49 \%$ of viable cells $)$ when compared to vehicle (100 $\pm 1.85 \%$ of viable cells). However, when SH-SY5Y cells were exposed to 6-OHDA, in the presence of $C$. tomentosum fractions $(100 \mu \mathrm{g} / \mathrm{mL})$, four samples exhibited capacity to revert (30-50\%) the neurotoxicity induced by 6-OHDA to values similar to the vitamin E standard $(90.11 \pm 3.74 \%$ of viable cells) (Figure 2B): MF2 (108.50 $\pm 4.53 \%$ of viable cells); DF1 (104.8\% $\pm 3.85 \%$ of viable cells); DF2 (89.15 $\pm 2.23 \%$ of viable cells); and DF5 (93.19 $\pm 2.53 \%$ of viable cells).

\subsection{Neuroprotective Effects of Codium tomentosum Fractions on PD Hallmarks}

To investigate whether the neuroprotective effects mediated by $C$. tomentosum fractions on SH-SY5Y cells' viability are associated with PD, several hallmarks were studied, namely oxidative stress, apoptosis, ROS production, changes in mitochondrial membrane potential, and Caspase- 3 activity. The results are depicted in Figure 3. 

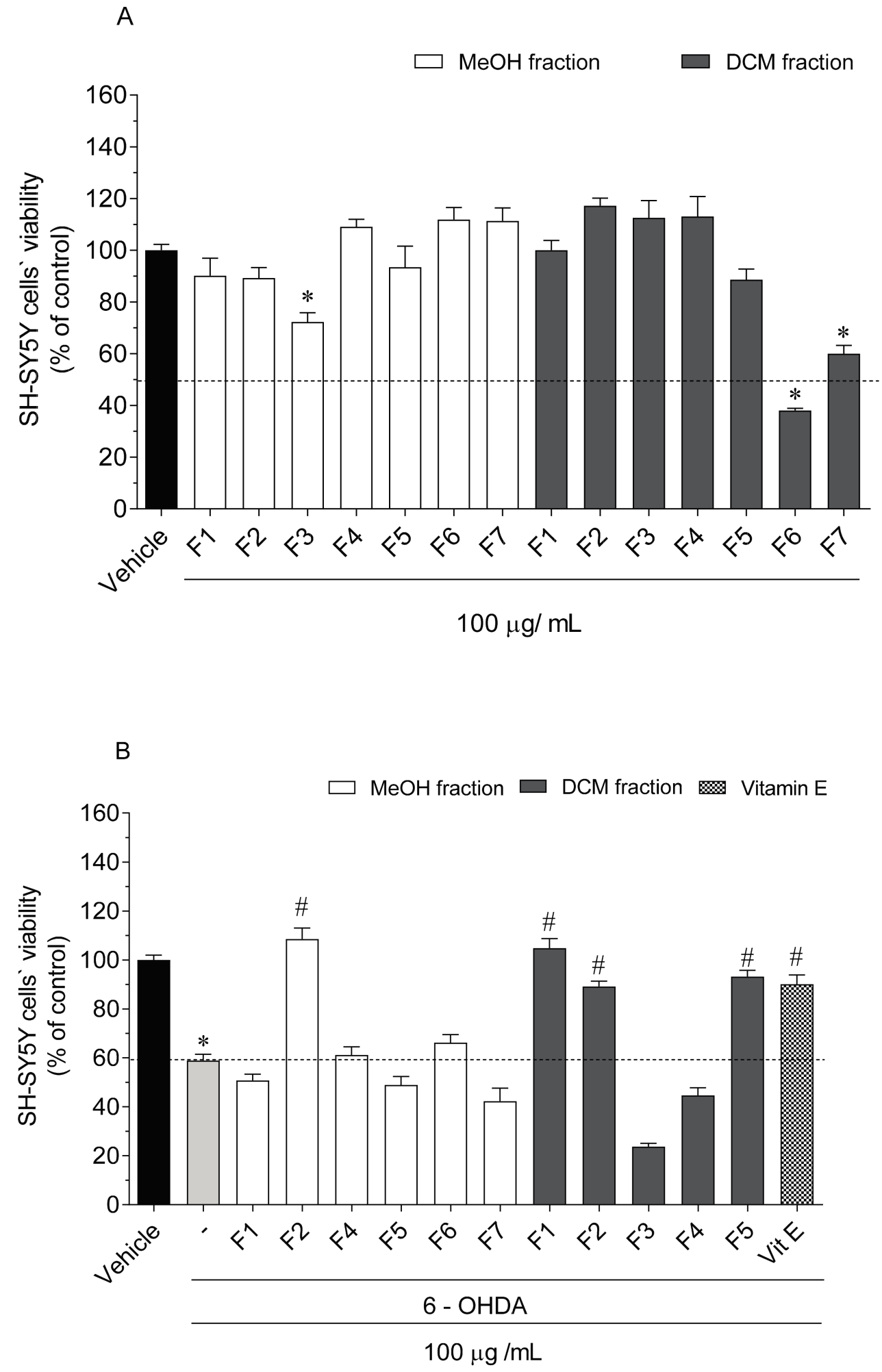

Figure 2. (A) Neurotoxicity of Codium tomentosum fractions $(100 \mu \mathrm{g} / \mathrm{mL}, 24 \mathrm{~h})$ and (B) neuroprotective effects of non-neurotoxic fractions $(100 \mu \mathrm{g} / \mathrm{mL}, 24 \mathrm{~h})$ in the presence of 6-OHDA $(100 \mu \mathrm{M})$ on SH-SY5Y cells. (-) 6-OHDA; Vit E (Vitamin E). The values in each column represent the mean \pm standard error of the mean (SEM) of three or four independent experiments. Symbols represent significant differences (ANOVA, Dunnett's test, $p<0.05$ ) when compared to: * vehicle and \# 6-OHDA. 

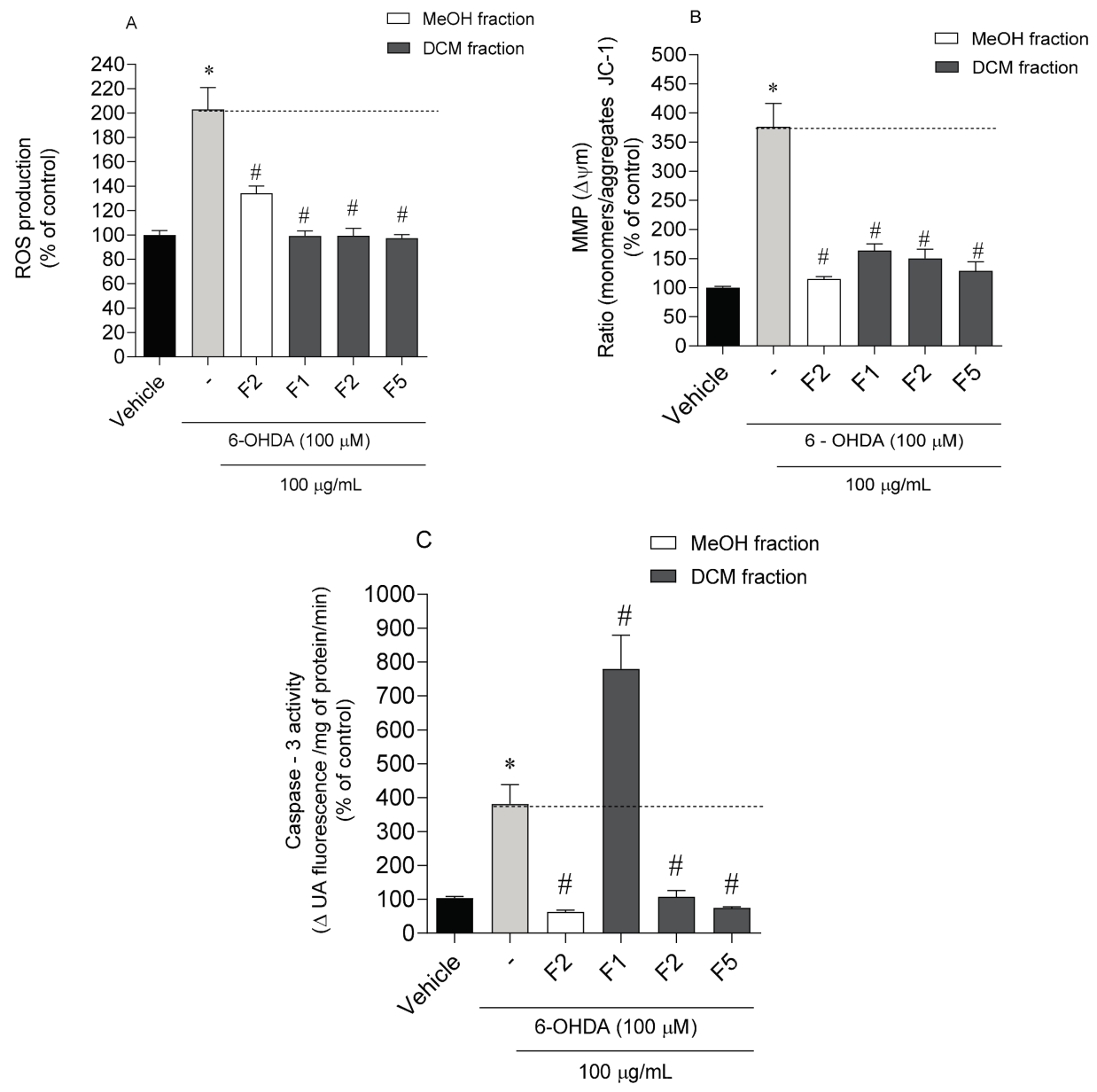

Figure 3. PD hallmarks evaluation on SH-SY5Y cells when exposed to 6-OHDA $(100 \mu \mathrm{M})$ and Codium tomentosum fractions $(100 \mu \mathrm{g} / \mathrm{mL} ; 6 \mathrm{~h})$. (A) ROS production; (B) changes in mitochondrial membrane potential; (C) Caspase-3 activity. (-) 6-OHDA. The values in each column represent the mean \pm standard error of the mean (SEM) of three or four independent experiments. Symbols represent significant differences (ANOVA, Dunnett's test, $p<0.05$ ) when compared to: * vehicle and \# 6-OHDA.

The exposition of SH-SY5Y cells to 6-OHDA led to a marked increase of ROS levels (203.1 $\pm 17.78 \%)$ when compared to vehicle $(100.00 \pm 3.53 \%)$ (Figure 3A). In the presence of $C$. tomentosum fractions, all of them induced a significant decrease of the ROS levels being the highest reduction mediated by DF1 and DF5 fractions (101.58 $\pm 8.44 \%$ and $101.17 \pm 4.15 \%$, respectively).

To understand if the neuroprotective effects of $C$. tomentosum fractions were mediated by biological events on mitochondria, possible changes on MMP were studied. The exposition of SH-SY5Y cells to 6-OHDA induced a strong depolarization of the MMP $(376.40 \pm 39.96 \%)$ when compared with the vehicle $(100.00 \pm 2.05 \%)$ (Figure $3 \mathrm{~B})$. On the other hand, the treatment conducted with seaweed fractions exhibited a preventive effect on MMP against the depolarization induced by 6-OHDA ( $376.40 \pm 39.96 \%)$, with the highest effect being mediated by MF2 $(114.90 \pm 4.04 \%)$ and DF5 fractions (128.60 $\pm 15.83 \%)$. Caspase- 3 activity was determined to understand if the neuroprotective effects of $C$. tomentosum fractions were mediated by apoptotic pathways. The exposure of SH-SY5Y cells to 6-OHDA increased its activity $(381.30 \pm 57.13 \%)$ when compared with the vehicle $(100.00 \pm 4.83 \%)$ (Figure 3C). On the other hand, the treatment with MF2 (62.70 $\pm 5.59 \%)$, DF2 $(107.10 \pm 18.77 \%)$, and DF5 $(74.43 \pm 3.55 \%)$ fractions led to a marked decrease in Caspase-3 activity. 


\subsection{Chemical Characterization of Codium tomentosum Bioactive Fractions}

A preliminary chemical characterization of the most bioactive fractions (MF2, DF1, DF2 and DF5) of C. tomentosum was performed by GC-MS. The compounds were tentatively identified by matching their mass spectra with those of reference compounds stored in the GC-MS mass spectral databases, evidencing the presence of different chemical groups such as terpenes, alcohols, carboxylic acids, esters, ketones and hydrocarbons. In fraction MF2, the presence of alkenes (1-docosene, 9-eicosene, 1-hexacosene), the fatty alcohol 1-tricosanol, and the glycol 1,2-octodecanediol was verified. Three alkanes (cyclohexadecane, eicosane, docosane), the heptafluorobutanoic acid and sebacic acid, bis (2-ethylhexyl) ester, one alcohol (2-hexyl-1-decanol), and one aldehyde (octadecanal) were detected in fraction DF1. Regarding fraction DF2, besides 2-methylundecanal and pentafluoropropionic acid, heptadecyl ester, the alcohols 2-hexyl-1-decanol and 1-tricosanol were also identified in this fraction. Finally, the monoterpenoid lactone loliolide, together with the glycol 1,2-octadecanediol, and the hexanedioic acid, bis (2-ethylhexyl) ester, were detected in fraction DF5. A terpene ketone (perhydrofarnesyl acetone) was present in fractions MF2, DF2, and DF5. Although in small amounts, these last two fractions also evidenced the presence of two peaks with characteristic mass fragmentation patterns of sterols. Additional data concerning compounds identification are available in Table S1 (Supplementary Information).

\section{Discussion}

Marine compounds have shown potential as possible therapeutic agents that can slow the processes associated with neuronal cell loss in neurodegenerative diseases, having ability to act in distinct biological targets.

Oxidative stress is believed to be one of the main triggers of neurodegenerative diseases, particularly in PD, and several studies have been carried out to understand the neuroprotective effects of antioxidant molecules [19]. These molecules have been widely discussed by several researchers as a possible therapy against neuronal death, as they have the ability to neutralize free radicals. In the present study, the antioxidant and neuroprotective potential of fractions from the green seaweed C. tomentosum were evaluated. Regarding their antioxidant capacity, three complementary methods (DPPH, FRAP, ORAC) were assayed and the results correlated with total phenolic content (TPC). None of the tested fractions showed significant antioxidant potential, which can be correlated with their low TPC levels. These results are in accordance with those reported by Pinteus and co-workers [9], who conducted an antioxidant screening of 27 algae collected from the Peniche coast (Portugal) in which green algae also did not show a relevant antioxidant capacity, when compared with other red and brown species. In recent years, the antioxidant potential of seaweeds has been fully documented in the literature $[8,9,19]$, and has been attributed to the presence of a wide variety of chemical structures with high antioxidant capacity such as phenols, flavonoids, phlorotannins, sulfated polysaccharides and ascorbic acid [20].

Several mechanisms are involved in neuroprotection and, although without an expressive antioxidant ability, C. tomentosum fractions were evaluated for their neuroprotective potential in an in vitro model of PD. Marine extracts and derived compounds have been previously reported by several studies to exhibit neuroprotective effects against 6-OHDA neurotoxicity and, consequently, this model has been widely used to mimic experimental models of PD $[8,13,20,21]$. In this study, it is shown that $C$. tomentosum fractions are able to promote cells recover from the toxicity induced by 6-OHDA exposition. Our results are consistent with other studies in which $C$. tomentosum dichloromethane extracts increased neuronal cells' viability in 35\%, blocking the toxic effects of 6-OHDA [13]. Although the mechanisms responsible for inducing cell death in PD have not been totally clarified, oxidative stress is clearly involved, due to an increase of ROS, resulting in mitochondrial impairment, lipid peroxidation, DNA damage, and cell death [21,22].

Producing about $90 \%$ of cellular ROS, mitochondria have a major role in oxidative stress related diseases. In fact, mitochondrial dysfunction has long been implicated in PD pathogenesis [23]. 
The production of ROS by inhibition of Complex I is a key mechanism for dopaminergic (DA) neuronal damage as DA neurons are susceptible to oxidative stress due to dopamine autoxidation. The generation of ROS also induces the damage of Complex I and III and the oxidation of mitochondrial and cytoplasmic proteins, leading to their dysfunction $[23,24]$. Based on the results obtained in the present work, it was found that DF1, DF2 and DF5 fractions were able to prevent ROS production and mitochondrial dysfunction promoted by 6-OHDA. These results are in agreement with those previously obtained with the seaweed Bifurcaria bifurcata [8], in which its dichloromethane fractions prevented cell death, maintained mitochondrial function and reduced ROS production. Souza et al. [15] also demonstrated, in the same in vitro model, that kappa-carrageenan from the algae Hypnea musciformis, prevented mitochondrial potential changes and reduced $\mathrm{H}_{2} \mathrm{O}_{2}$ production. Additionally, several authors reported the neuroprotective properties of seaweed derived polysaccharides on 6-OHDA-induced neurotoxicity in SH-SY5Y cells [24-26].

Besides oxidative stress and mitochondrial dysfunction, apoptosis has also been implicated in neuronal death in PD [27]. These mechanisms are mediated by several initiators and executer caspases, via intrinsic or extrinsic pathways. The initiating caspases ( -9 and -8$)$ converge onto a common pathway of executioner caspases involving Caspase -3 and -6 . The activation of executioner caspases leads to morphological features of apoptosis, such as DNA cleavage and its subsequent fragmentation. Based on the results presented here, it was verified that fractions MF2, DF2, and DF5 prevented the increase of Caspase -3 activity promoted by 6-OHDA.

A preliminary chemical screening of $C$. tomentosum most promising bioactive fractions was carried out by GC-MS analysis, and several compounds belonging to different chemical classes were identified, e.g., terpenes, fatty alcohols, carboxylic acids, aldehydes, esters, ketones, saturated and unsaturated hydrocarbons. Accordingly, Valentão et al. [18] also detected compounds belonging to some of the above described chemical classes in C. tomentosum, collected at Espinho coast (Portugal). The GC-MS analysis of other Codium species, like C. bursa, also suggested the presence of components belonging to the above described structural groups [26]. Numerous constituents from natural resources, namely those of marine origin having different structural features are reported for their neuroprotective properties [28-31]. Among the less polar compounds, there is great evidence that lipids play a central role in PD [32]; however, current data are still too preliminary, and more detailed studies about this issue are needed. Nevertheless, given the lipidic richness of C. tomentosum [18,33-35], the hypothesis that lipidic and other less polar constituents, including sterols [36], can be involved in the neuroprotection must not be discarded. As reported by Zhang et al. [37] the lipophilicity enhances the blood-brain barrier (BBB) penetration ability, even though BBB penetration is a highly complex process and a result of many cooperative effects. Effectively, one of the main bottlenecks associated with the development of new therapeutics for PD is the difficulty of many drugs to reach the brain, due to this highly selective semi-permeant barrier that protects brain and the spinal cord from many foreign substances. It is critical the development of deeper investigation studies in more complex in vitro models, such as co-cultures, to understand the ability of $C$. tomentosum-derived compounds to cross the BBB, and the possibility of their incorporation in smart delivery systems such as nanoparticles for brain drug delivery, tissue engineering, and new biomaterials [38]. This strategy will contribute to refine the selection of the most active compounds with neuroprotective potential suppressing the gap between in vitro and in vivo assays.

In conclusion, the current lack of studies on seaweed-derived neuroprotective agents evidences the relevance of $C$. tomentosum as a source of new compounds with potential neuroprotective properties, opening new research lines. This work showed that its bioactive fractions markedly inhibited 6-OHDA neurotoxicity induced in human neuroblastoma SH-SY5Y cells. Our results suggest that the neuroprotective effects are mediated by the mitigation of ROS generation and mitochondrial dysfunctions, together with the reduction of Caspase- 3 activity. To the best of our knowledge, this is the first study focusing on the neuroprotective capacity of $C$. tomentosum in the in vitro PD model here described. Work is ongoing regarding the isolation and chemical characterization of promising 
constituents from the most bioactive fractions as well as compounds' bioavailability studies on in vitro models that mimic the BBB. Nevertheless, the possibility of synergistic effects between the identified constituents need to be considered and can be regarded as an advantage, since Codium spp. is an edible seaweed that can be explored for nutraceutical and prophylactic purposes to overcome PD impairments.

\section{Materials and Methods}

\subsection{Collection and Preparation of Codium tomentosum Samples}

The green seaweed Codium tomentum Stackouse, 1797 was collected in October 2016 at Peniche coast, Portugal $\left(39^{\circ} 37^{\prime} 05^{\prime \prime} \mathrm{N},-9^{\circ} 38^{\prime} 58^{\prime \prime} \mathrm{O}\right)$, and transported to MARE-Polytechnic of Leiria lab facilities. The seaweed was rinsed carefully with seawater and distilled water to remove epiphytes, sand and debris. Then, it was freeze-dried (Scanvac Cool Safe, LaboGene, Lynge, Denmark), ground, and stored in a cool place protected from light, until further use.

\subsection{Seaweed Extraction and Fractionation}

Freeze-dried samples of $C$. tomentosum $(445 \mathrm{~g})$ were sequentially extracted with methanol $(\mathrm{MeOH})$ and dichloromethane (DCM) (VWR-BDH Chemicals, Fontenay-sous-Bois, France) (in a biomass/solvent ratio of 1:40) with constant stirring, overnight. Crude dried extracts were obtained using a rotary evaporator (IKA HB10, Staufen, Germany) and/or a speed vacuum equipment (Concentrator Plus, Eppendorf, Spain). The MeOH (112.64 g, 25.31\%) and DCM (6.47 g, 1.45\%) crude extracts were subjected to a normal phase vacuum liquid chromatography (VLC) on silica gel $60(0.06-0.2 \mathrm{~mm}$, VWR, Leuven, Belgium). Elution was performed by using cyclohexane with increasing amounts of ethyl acetate $(v / v)$ as the mobile phase: 1:0 (MF1, $0.02 \mathrm{~g}$; DF1, 0.06 g), 2:1 (MF2, $0.66 \mathrm{~g}$; DF2, 0.16 g), 2:2 (MF3, 0.18 g; DF3, 0.15 g) 1:2 (MF4, 0.11 g; DF4, 0.10 g) 0:1 (MF5, 0.13 g; DF5, 0.63 g), MeOH (MF6,1.35 g; DF6, $1.39 \mathrm{~g}$ ), and acetone (MF7, $3.38 \mathrm{~g}$; DF7 $0.86 \mathrm{~g}$ ), $400 \mathrm{~mL}$ of each eluent (Figure 1). Fractionation yields were determined in relation to biomass of freeze-dried seaweed. The fractions attained were subjected to a series of in vitro biological assays, in order to evaluate their antioxidant and neuroprotective potential.

\subsection{Quantification of Total Phenolic Content (TPC)}

The TPC of $C$. tomentosum fractions was determined using the Folin-Ciocalteu reagent (Sigma, Saint Louis, MO, USA) according to the method described by Singleton et al. [39] with slight modifications [8]. After $1 \mathrm{~h}$ of reaction in the dark, the absorbance was measured at $755 \mathrm{~nm}$ (Synergy H1 Multi-Mode Microplate Reader, BioTek ${ }^{\circledR}$ Instruments, Winooski, VT, USA). Gallic acid was used as standard and TPC is expressed as milligrams of gallic acid equivalents per gram of dry extract (mg GAE/g of extract).

\subsection{Evaluation of Antioxidant Activity}

\subsubsection{2-Diphenyl-1-picrylhydrazyl (DPPH) Radical Scavenging Activity}

The ability of $C$. tomentosum fractions to scavenge the DPPH radical was determined according to the protocol described by Pinteus et al. [9]. Briefly, the reaction mixtures were incubated in the dark, for $30 \mathrm{~min}$, at room temperature. The absorbance was then measured at $517 \mathrm{~nm}$. The samples were tested at a maximum concentration of $100 \mu \mathrm{g} / \mathrm{mL}$. A dose-response analysis $(10-100 \mu \mathrm{g} / \mathrm{mL})$ was performed for the samples with DPPH reduction $>50 \%$ for $\mathrm{EC}_{50}$ determination.

\subsubsection{Oxygen Radical Absorbance Capacity (ORAC-Fluorescein)}

The ability of seaweed fractions to neutralize peroxyl free radicals avoiding fluorescein oxidation was accomplished according to the protocol described by Dávalos et al. [40]. Samples $(20 \mu \mathrm{L})$, and fluorescein $(120 \mu \mathrm{L} ; 70 \mathrm{nM}$, final concentration) were added to a 96-well microplate and pre-incubated for $15 \mathrm{~min}$ at $37^{\circ} \mathrm{C}$. Ending this time, AAPH (2,2'-Azobis(2-methylpropionamidine) 
dihydrochloride (Sigma-Aldrich, Barcelona, Spain) solution $(60 \mu \mathrm{L} ; 12 \mathrm{mM}$, final concentration) was added quickly. The microplate was immediately placed in the reader and the fluorescence $(\lambda$ excitation: $458 \mathrm{~nm}$; $\lambda$ emission: $520 \mathrm{~nm}$ ) recorded every minute, for $240 \mathrm{~min}$. Trolox (Sigma-Aldrich, St. Louis, MO, USA) was used as an antioxidant standard. The results are expressed in $\mu \mathrm{mol}$ of Trolox equivalents/g of dry extract ( $\mu \mathrm{mol} \mathrm{TE} / \mathrm{g}$ of extract).

\subsubsection{Ferric Reducing Antioxidant Power (FRAP)}

The capacity of seaweed fractions to reduce $\mathrm{F}^{3+}$ to $\mathrm{F}^{2+}$ through electron donation was performed according to Benzie and Strain [41] with slight modifications [8]. FRAP reagent was prepared freshly with $0.3 \mathrm{M}$ acetate buffer ( $\mathrm{pH}=3.6), 10 \mathrm{mM}$ of 2,4,6-tri(2-pyridyl)-s-triazine, (TPTZ) (Alfa Aesar, Kandel, Germany) in $40 \mathrm{mM} \mathrm{HCl}$ and $20 \mathrm{mM}$ ferric solution using $\mathrm{FeCl}_{3}$ (10:1:1) and pre-heated at $37^{\circ} \mathrm{C}$. Briefly, $2 \mu \mathrm{L}$ of $\mathrm{C}$. tomentosum samples were added to $198 \mu \mathrm{L}$ of FRAP reagent and incubated at $37^{\circ} \mathrm{C}$ in the dark for $30 \mathrm{~min}$. $\mathrm{FeSO}_{4}$ was used as standard, and the absorbance was then read at $593 \mathrm{~nm}$. The difference between the absorbance of test fractions and the blank reading was calculated, and results expressed as $\mu \mathrm{M}$ of $\mathrm{FeSO}_{4} / \mathrm{g}$ of extract ( $\mu \mathrm{M} \mathrm{FeSO} / \mathrm{g}$ of extract).

\subsection{Evaluation of the Neuroprotective Potential of Codium tomentosum}

\subsubsection{Cell Culture Maintenance Conditions}

The biological activities of fractions were conducted on an in vitro cellular model of human neuroblastoma (SH-SY5Y cells, strain number ACC 209) previously acquired from DSMZ (Deutsche Sammlung von Mikroorganismen und Zellkulturen $\mathrm{GmbH}$ ) biobank. The cells were cultured according to the supplier's instructions. SH-SY5Y cells grew in DMEM:F12 medium (Biowest, Riverside, MO, USA) supplemented with 10\% ( $v / v$ ) fetal bovine serum (Biowest, Riverside, MO, USA) and 1\% of antibiotic mixture constituted by $1 \%$ penicillin/streptomycin (Sigma, Rehovot, Israel). SH-SY5Y cells were maintained in a humidified atmosphere with $5 \% \mathrm{CO}_{2}$ at $37^{\circ} \mathrm{C}$.

\subsubsection{Neurotoxic and Neuroprotective Potential}

The neurotoxicity was evaluated on SH-SY5Y cells at 75-85\% of total confluence. Cells were treated with seaweed fractions $(100 \mu \mathrm{g} / \mathrm{mL})$ for $24 \mathrm{~h}$ to determine and select the non-neurotoxic samples/concentrations for the next assays. Regarding the neuroprotective assay, SH-SY5Y cells were exposed to 6-OHDA $(100 \mu \mathrm{M})$ (Sigma, St. Louis, MO, USA) in the presence/absence of non-neurotoxic seaweed fractions $(100 \mu \mathrm{g} / \mathrm{mL})$. The effects on SH-SY5Y cells' viability was then estimated by the MTT (3-(4,5-dimethyl-2-thiazolyl)-2,5-diphenyl-2H-tetrazolium bromide) assay (VWR, Solon, OH, USA). Cells were incubated with MTT $(1.2 \mathrm{mM})$ for $1 \mathrm{~h}$ at $37^{\circ} \mathrm{C}$. Ending this time, $100 \mu \mathrm{L}$ of dimethyl sulfoxide (DMSO) were added, and the absorbance read at $570 \mathrm{~nm}$ (Synergy H1 Multi-Mode Microplate Reader, BioTek ${ }^{\circledR}$ Instruments, Winooski, VT, USA). The results were expressed as percentage of the control.

\subsubsection{Neuroprotective Effects on PD Biomarkers}

\section{Determination of Intracellular Reactive Oxygen Species (ROS) Levels}

The ROS levels were determined using the oxidation sensitive fluoroprobe 5(6)-carboxy-2', $7^{\prime}$ dichlorofluorescein diacetate (carboxy-H2DCFDA) (Invitrogen, Bleiswijk, Netherlands) according to Ouazia et al. [42] with slight modifications. Briefly, SH-SY5Y cells were exposed to 6-OHDA $(100 \mu \mathrm{M})$ in the presence/absence of seaweed fractions $(100 \mu \mathrm{g} / \mathrm{mL})$ for $6 \mathrm{~h}$. Cells were then washed with phosphate buffered saline (PBS) and incubated with carboxy-H2DCFDA $(20 \mu \mathrm{M})$ probe, previously dissolved in serum-free medium for $1 \mathrm{~h}$ at $37^{\circ} \mathrm{C}$. Ending this time, the fluorescence was read ( $\lambda$ excitation: $527 \mathrm{~nm}$; $\lambda$ emission: $495 \mathrm{~nm}$ ). 
Mitochondrial Membrane Potential (MMP)

Analysis of MMP was performed using the JC-1 fluorescent dye (Molecular Probes, Eugene, OR, USA) according to Silva et al. [8]. SH-SY5 cells were exposed to 6-OHDA (100 $\mu$ M) in the presence/absence of seaweed fractions $(100 \mu \mathrm{g} / \mathrm{mL})$ for $6 \mathrm{~h}$. Cells were then washed with PBS and incubated with JC-1 solution $(3 \mu \mathrm{M})$ in the dark, for $15 \mathrm{~min}$, at $37^{\circ} \mathrm{C}$. After this time, the JC- 1 dye was removed, and PBS was added to wells. The fluorescence was read at $530 \mathrm{~nm}$ (monomers) and at $590 \mathrm{~nm}$ (aggregates) and $490 \mathrm{~nm}$ emission/excitation wavelengths, respectively. The results were calculated from the ratio between JC-1 monomers and aggregates and are expressed in percentage of control.

\section{Caspase-3 Activity}

Caspase-3 activity was evaluated using the caspase-3 fluorometric assay kit (CASP3F-KIT, Sigma, St. Louis, MO, USA) according to the manufacturers' instructions. Briefly, SH-SY5Y cells were treated with 6-OHDA $(100 \mu \mathrm{M})$ in the presence/absence of seaweed fractions $(100 \mu \mathrm{g} / \mathrm{mL})$ for $6 \mathrm{~h}$. Ending treatment time, cells were washed with PBS, harvested, and enzyme activity determined by reading the fluorescence at $360 \mathrm{~nm}$ and $460 \mathrm{~nm}$ emission and excitation wavelengths, respectively. The results were calculated from the slope of the curve and are expressed in percentage of control.

\subsection{Chemical Characterization of Codium tomentosum Bioactive Samples}

Gas Chromatography-Mass Spectrometry (GC-MS) Analysis

GC-MS qualitative analysis was performed in a Shimadzu QP2010-Plus GC/MS system equipped with a TRB5MS $(30 \mathrm{~m} \times 0.25 \mathrm{~mm}$ i.d. $\times 0.25 \mu \mathrm{m}$ film thickness) capillary column (Teknokroma, Barcelona, Spain) operating in the linear velocity mode. The carrier gas was helium 5.0 (Linde, Lisboa, Portugal), with a constant flow of $1 \mathrm{~mL} / \mathrm{min}$. Samples were dissolved in dichloromethane and automatically injected. Injections were performed in split mode, with a ratio of $1 / 9$. The injector port was heated to $280{ }^{\circ} \mathrm{C}$. The initial column temperature of $60{ }^{\circ} \mathrm{C}$ was held for $2 \mathrm{~min}$, followed by a temperature ramp of $30{ }^{\circ} \mathrm{C} / \mathrm{min}$ to $300{ }^{\circ} \mathrm{C}$ held for $15 \mathrm{~min}$. All mass spectra were acquired in electron impact (EI) mode at $70 \mathrm{eV}$. The operate temperatures were $200{ }^{\circ} \mathrm{C}$ for MS ion source, and $250{ }^{\circ} \mathrm{C}$ for the liner interface. Analysis were performed in full scan mode with mass ranging from 10 to $800 \mathrm{~m} / \mathrm{z}$. Compounds were identified by matching the mass fragmentation patterns with those stored in the GC-MS mass spectral databases (Wiley 229 and NIST-National Institute of Standards and Technology libraries).

\subsection{Data and Statistical Analysis}

When applicable, results are presented as mean \pm standard error of the mean (SEM). The determination of $\mathrm{EC}_{50}$ was attained from sigmoidal dose-response variable-slope curves using the GraphPad Prism v.8 software (GraphPad Software Inc., San Diego, CA, USA). One-way analysis of variance (ANOVA) with Dunnett's multiple comparison of group means was employed to determine significant differences relatively to the control treatment. All other post hoc analyses were conducted using Tukey's test. All data were checked for normality and homoscedasticity. Comparisons concerning variables, which did not meet variance or distributional assumptions, were carried out with Kruskal-Wallis non-parametric tests. At least three independent experiments were carried out in triplicate.

Supplementary Materials: The following are available online, Table S1: Identification of compounds in Codium tomentosum bioactive fractions by GC-MS.

Author Contributions: J.S. and C.A. did main experiments (antioxidant, cytotoxicity, neuroprotective, signal pathway mechanisms), A.M. and S.P. were involved in the extraction and fractionation processes. A.M. and H.G. were involved in chemical characterization procedures. J.S., A.M., C.A. and S.P. drafted the document. All the authors were involved in the research topic and designed the study. R.P. and A.A. coordinated the study. All authors read and approved the final manuscript and are accountable for the integrity of this manuscript. 
Funding: This work was supported by the Portuguese Foundation for Science and Technology (FCT) through the strategic project UID/MAR/04292/2020 to MARE-Marine and Environmental Sciences Centre and UID/Multi/04046/2020 and UIDB/04046/2020 granted to BioISI—BioSystems and Integrative Sciences Institute, through POINT4PAC project (Oncologia de Precisão: Terapias e Tecnologias Inovadoras, SAICTPAC/0019/ 2015-LISBOA- 01-0145-FEDER-016405), through CROSS-ATLANTIC project (PTDC/BIA-OUT/29250/2017), co-financed by COMPETE (POCI-01-0145-FEDER-029250) and through Molecules for Health project (PTDC) BIA-BQM/28355/2017). This work was also funded by the Integrated Programme of SR\&TD Smart Valorization of Endogenous Marine Biological Resources Under a Changing Climate (Centro-01-0145-FEDER-000018), co-funded by Centro 2020 Programme, Portugal 2020, European Union, through the European Regional Development Fund.

Acknowledgments: The authors are very grateful for the financial support of the Projects and Programmes described in the funding section. FCT is also acknowledged for the grants attributed to JS (SFRH/BD/103255/2014), and SP (SFRH/BD/96203/2013).

Conflicts of Interest: The authors declare no conflict of interest.

\section{References}

1. Pangestuti, R.; Kim, S.-K. Neuroprotective effects of marine algae. Mar. Drugs 2011, 9, 803-818. [CrossRef]

2. El Gamal, A.A. Biological importance of marine algae. Saudi Pharm. J. 2010, 18, 1-25. [CrossRef]

3. Harris, J.R. Protein Aggregation and Fibrillogenesis in Cerebral and Systemic Amyloid Disease; Springer Science \& Business Media: Berlin/Heidelberg, Germany, 2012; Volume 65.

4. Hussain, R.; Zubair, H.; Pursell, S.; Shahab, M. Neurodegenerative diseases: Regenerative mechanisms and novel therapeutic approaches. Brain Sci. 2018, 8, 177. [CrossRef] [PubMed]

5. Radhakrishnan, D.M.; Goyal, V. Parkinson's disease: A review. Neurol. India 2018, 66, 26.

6. Del Rey, N.L.-G.; Quiroga-Varela, A.; Garbayo, E.; Carballo-Carbajal, I.; Fernández-Santiago, R.; Monje, M.H.; Trigo-Damas, I.; Blanco-Prieto, M.J.; Blesa, J. Advances in Parkinson's disease: 200 years later. Front. Neuroanat. 2018, 12, 113. [CrossRef] [PubMed]

7. Sarkar, S.; Raymick, J.; Imam, S. Neuroprotective and therapeutic strategies against Parkinson's disease: Recent perspectives. Int. J. Mol. Sci. 2016, 17, 904. [CrossRef]

8. Silva, J.; Alves, C.; Freitas, R.; Martins, A.; Pinteus, S.; Ribeiro, J.; Gaspar, H.; Alfonso, A.; Pedrosa, R. Antioxidant and Neuroprotective Potential of the Brown Seaweed Bifurcaria bifurcata in an in vitro Parkinson's Disease Model. Mar. Drugs 2019, 17, 85. [CrossRef]

9. Pinteus, S.; Silva, J.; Alves, C.; Horta, A.; Fino, N.; Rodrigues, A.I.; Mendes, S.; Pedrosa, R. Cytoprotective effect of seaweeds with high antioxidant activity from the Peniche coast (Portugal). Food Chem. 2017, 218, 591-599. [CrossRef]

10. Pinteus, S.; Alves, C.; Monteiro, H.; Araújo, E.; Horta, A.; Pedrosa, R. Asparagopsis armata and Sphaerococcus coronopifolius as a natural source of antimicrobial compounds. World J. Microbiol. Biotechnol. 2015, 31, 445-451. [CrossRef]

11. Mhadhebi, L.; Mhadhebi, A.; Robert, J.; Bouraoui, A. Antioxidant, Anti-inflammatory and Antiproliferative Effects of Aqueous Extracts of Three Mediterranean Brown Seaweeds of the Genus Cystoseira. Iran J. Pharm. Res. 2014, 13, 207-220.

12. Alves, C.; Pinteus, S.; Rodrigues, A.; Horta, A.; Pedrosa, R. Algae from Portuguese coast presented high cytotoxicity and antiproliferative effects on an in vitro model of human colorectal cancer. Pharmacogn. Res. 2018, 10, 24.

13. Silva, J.; Alves, C.; Pinteus, S.; Mendes, S.; Pedrosa, R. Neuroprotective effects of seaweeds against 6-hydroxydopamine-induced cell death on an in vitro human neuroblastoma model. BMC Complement. Altern. Med. 2018, 18, 1-10. [CrossRef] [PubMed]

14. Hannan, M.A.; Dash, R.; Haque, M.N.; Mohibbullah, M.; Sohag, A.A.M.; Rahman, M.A.; Uddin, M.J.; Alam, M.; Moon, I.S. Neuroprotective potentials of marine algae and their bioactive metabolites: Pharmacological insights and therapeutic advances. Mar. Drugs 2020, 18, 347. [CrossRef]

15. Souza, R.B.; Frota, A.F.; Silva, J.; Alves, C.; Neugebauer, A.Z.; Pinteus, S.; Rodrigues, J.A.G.; Cordeiro, E.M.S.; de Almeida, R.R.; Pedrosa, R. In vitro activities of kappa-carrageenan isolated from red marine alga Hypnea musciformis: Antimicrobial, anticancer and neuroprotective potential. Int. J. Biol. Macromol. 2018, 112, 1248-1256. [CrossRef] [PubMed]

16. Wen, Z.-H.; Chao, C.-H.; Wu, M.-H.; Sheu, J.-H. A neuroprotective sulfone of marine origin and the in vivo anti-inflammatory activity of an analogue. Eur. J. Med. Chem. 2010, 45, 5998-6004. [CrossRef] 
17. Gao, Y.; Dong, C.; Yin, J.; Shen, J.; Tian, J.; Li, C. Neuroprotective effect of fucoidan on $\mathrm{H}_{2} \mathrm{O}_{2}$-induced apoptosis in PC12 cells via activation of PI3K/Akt pathway. Cell. Mol. Neurobiol. 2012, 32, 523-529. [CrossRef]

18. Valentão, P.; Trindade, P.; Gomes, D.; de Pinho, P.G.; Mouga, T.; Andrade, P.B. Codium tomentosum and Plocamium cartilagineum: Chemistry and antioxidant potential. Food Chem. 2010, 119, 1359-1368. [CrossRef]

19. Niedzielska, E.; Smaga, I.; Gawlik, M.; Moniczewski, A.; Stankowicz, P.; Pera, J.; Filip, M. Oxidative stress in neurodegenerative diseases. Mol. Neurobiol. 2016, 53, 4094-4125. [CrossRef]

20. Kim, D.-W.; Lee, K.-T.; Kwon, J.; Lee, H.J.; Lee, D.; Mar, W. Neuroprotection against 6-OHDA-induced oxidative stress and apoptosis in SH-SY5Y cells by 5, 7-Dihydroxychromone: Activation of the Nrf2/ARE pathway. Life Sci. 2015, 130, 25-30. [CrossRef]

21. Ferlazzo, N.; Cirmi, S.; Maugeri, A.; Russo, C.; Lombardo, G.E.; Gangemi, S.; Calapai, G.; Mollace, V.; Navarra, M. Neuroprotective Effect of Bergamot Juice in 6-OHDA-Induced SH-SY5Y Cell Death, an In Vitro Model of Parkinson's Disease. Pharmaceutics 2020, 12, 326. [CrossRef]

22. Rodriguez-Pallares, J.; Parga, J.; Munoz, A.; Rey, P.; Guerra, M.; Labandeira-Garcia, J. Mechanism of 6-hydroxydopamine neurotoxicity: The role of NADPH oxidase and microglial activation in 6-hydroxydopamine-induced degeneration of dopaminergic neurons. J. Neurochem. 2007, 103, 145-156. [CrossRef] [PubMed]

23. Hu, Q.; Wang, G. Mitochondrial dysfunction in Parkinson's disease. Transl. Neurodegener. 2016, 5, 1-8. [CrossRef] [PubMed]

24. Abou-Sleiman, P.M.; Muqit, M.M.; Wood, N.W. Expanding insights of mitochondrial dysfunction in Parkinson's disease. Nat. Rev. Neurosci. 2006, 7, 207-219. [CrossRef] [PubMed]

25. Wang, B.; Liu, Q.; Huang, Y.; Yuan, Y.; Ma, Q.; Du, M.; Cai, T.; Cai, Y. Extraction of polysaccharide from Spirulina and evaluation of its activities. Evid.-Based Complementary Altern. Med. 2018. [CrossRef]

26. Jerković, I.; Kranjac, M.; Marijanović, Z.; Šarkanj, B.; Cikoš, A.-M.; Aladić, K.; Pedisić, S.; Jokić, S. Chemical Diversity of Codium bursa (Olivi) C. Agardh Headspace Compounds, Volatiles, Fatty Acids and Insight into Its Antifungal Activity. Molecules 2019, 24, 842. [CrossRef] [PubMed]

27. Erekat, N.S. Apoptosis and its Role in Parkinson's Disease. Exon Publ. 2018. [CrossRef]

28. Mohd Sairazi, N.S.; Sirajudeen, K. Natural Products and Their Bioactive Compounds: Neuroprotective Potentials against Neurodegenerative Diseases. Evid.-Based Complement. Altern. Med. 2020. [CrossRef]

29. Bălașa, A.F.; Chircov, C.; Grumezescu, A.M. Marine Biocompounds for Neuroprotection-A Review. Mar. Drugs 2020, 18, 290. [CrossRef]

30. Huang, C.; Zhang, Z.; Cui, W. Marine-derived natural compounds for the treatment of Parkinson's disease. Mar. Drugs 2019, 17, 221. [CrossRef]

31. Carrera, I.; Cacabelos, R. Current drugs and potential future neuroprotective compounds for Parkinson's disease. Curr. Neuropharmacol. 2019, 17, 295-306. [CrossRef]

32. Xicoy, H.; Wieringa, B.; Martens, G.J. The role of lipids in Parkinson's disease. Cells 2019, 8, 27. [CrossRef]

33. Rodrigues, D.; Alves, C.; Horta, A.; Pinteus, S.; Silva, J.; Culioli, G.; Thomas, O.P.; Pedrosa, R. Antitumor and antimicrobial potential of bromoditerpenes isolated from the red alga, Sphaerococcus coronopifolius. Mar. Drugs 2015, 13, 713-726. [CrossRef] [PubMed]

34. Rey, F.; Cartaxana, P.; Melo, T.; Calado, R.; Pereira, R.; Abreu, H.; Domingues, P.; Cruz, S.; Domingues, M.R. Domesticated populations of Codium tomentosum display lipid extracts with lower seasonal shifts than conspecifics from the wild-relevance for biotechnological applications of this green seaweed. Mar. Drugs 2020, 18, 188. [CrossRef] [PubMed]

35. da Costa, E.; Melo, T.; Moreira, A.S.; Alves, E.; Domingues, P.; Calado, R.; Abreu, M.H.; Domingues, M.R. Decoding bioactive polar lipid profile of the macroalgae Codium tomentosum from a sustainable IMTA system using a lipidomic approach. Algal Res. 2015, 12, 388-397. [CrossRef]

36. Lopes, G.; Sousa, C.; Bernardo, J.; Andrade, P.B.; Valentão, P.; Ferreres, F.; Mouga, T. Sterol profiles in 18 macroalgae of the portuguese coast. J. Phycol. 2011, 47, 1210-1218. [CrossRef] [PubMed]

37. Zhang, D.; Xiao, J.; Zhou, N.; Zheng, M.; Luo, X.; Jiang, H.; Chen, K. A genetic algorithm based support vector machine model for blood-brain barrier penetration prediction. BioMed Res. Int. 2015. [CrossRef] [PubMed]

38. Akhtar, A.; Andleeb, A.; Waris, T.S.; Bazzar, M.; Moradi, A.-R.; Awan, N.R.; Yar, M. Neurodegenerative diseases and effective drug delivery: A review of challenges and novel therapeutics. J. Control. Release 2020. [CrossRef] 
39. Singleton, V.L.; Rossi, J.A. Colorimetry of total phenolics with phosphomolybdic-phosphotungstic acid reagents. Am. J. Enol. Vitic. 1965, 16, 144-158.

40. Dávalos, A.; Gómez-Cordovés, C.; Bartolomé, B. Extending applicability of the oxygen radical absorbance capacity (ORAC- fluorescein) assay. J. Agric. Food Chem. 2004, 52, 48-54. [CrossRef]

41. Benzie, I.F.; Strain, J.J. The ferric reducing ability of plasma (FRAP) as a measure of "antioxidant power": The FRAP assay. Anal. Biochem. 1996, 239, 70-76. [CrossRef]

42. Ouazia, D.; Levros, L.-C., Jr.; Rassart, E.; Desrosiers, R. Dopamine down-regulation of protein L-isoaspartyl methyltransferase is dependent on reactive oxygen species in SH-SY5Y cells. Neuroscience 2014, 267, $263-276$. [CrossRef] [PubMed]

Sample Availability: Samples of the compounds are available from the authors.

Publisher's Note: MDPI stays neutral with regard to jurisdictional claims in published maps and institutional affiliations.

(C) 2020 by the authors. Licensee MDPI, Basel, Switzerland. This article is an open access article distributed under the terms and conditions of the Creative Commons Attribution (CC BY) license (http://creativecommons.org/licenses/by/4.0/). 